\title{
Comparative Analysis of the Fuel Properties of Ethylester Biodiesels from Cyperus esculentus, Sesamum indicum and Colocynthus vulgaris Seed Oils
}

\author{
Anekwe Ozioma Juliana, Ajiwe Vincent Ishmael Egbulefu \\ Department of Pure and Industrial Chemistry, Nnamdi Azikiwe University, Awka, Anambra State, Nigeria
}

Email address:

oziane2002@yahoo.com (A. O.Juliana),Vaj_04@yahoo.com (A. V. I. Egbulefu)

To cite this article:

Anekwe Ozioma Juliana, Ajiwe Vincent Ishmael Egbulefu. Comparative Analysis of the Fuel Properties of Ethylester Biodiesels from Cyperus esculentus, Sesamum indicum and Colocynthus vulgaris Seed Oils. Journal of Energy and Natural Resources.

Vol. 4, No. 3, 2015, pp. 40-44. doi: 10.11648/j.jenr.20150403.11

\begin{abstract}
The relative abundance of some Nigerian seed oils coupled with the little knowledge of their biodiesel usage prompted the need for this research. Biodiesel production is a very modern and technological area for researchers due to the relevance that it is winning everyday because of the increase in the petroleum price and the environmental advantages. In this work, studies were carried out to investigate the fuel properties of Cyperus esculentus, Colocynthus vulgaris, Sesamum indicum ethylesters and their corresponding ethyl ester blends. Ethylesters of these oils were prepared by $\mathrm{H}_{2} \mathrm{SO}_{4}$ catalysed transesterification reaction between the oils and ethanol. The fuel properties such as kinematic viscosity, flash points, pour point and water crackle were determined. GC-MS was used to determine the fatty acid profile of the transesterified oils. The fuel properties correlated very well with the fatty acid compositions. The results showed that the oils were rich in saturated fatty acids (66.67\%), appreciable value of monounsaturated fatty acids (33.33\%) and little percent (33.33\%) polyunsaturated fatty acids and absence of polyunsaturated fatty acids in Cyperus esculentus and Sesamum indicum esters. The fatty acid chain lengths that were predominant in Cyperus esculentus, Colocynthus vulgaris, Sesamum indicum were C16, C18 and C20. The fuel properties of Colocynthus vulgaris, Cyperus esculentus and Sesamum indicum biodiesel blends were better when compared to the oil and petrodiesel in terms of flash points, viscosity and pour points, hence the optimum engine performance of both oil and petrodiesel could be improved by use of these biodiesel feedstock.
\end{abstract}

Keywords: Ethylbiodiesels, Cyperus esculentus, Colocynthus vulgaris, Sesamum indicum, Comparative Analysis

\section{Introduction}

Escalating crude oil prices and environmental awareness have increased interest in the use of renewable fuel sources. One area of attention is the upgrading of vegetable oils for use as a fuel or fuel additive. Besides being a renewable source, the use of vegetable oils has benefits economically and environmentally. Such oils are $\mathrm{CO}_{2}$ neutral and contain little, if any sulfur, nitrogen and metals, which are major pollutants in current fuel emissions (Katikaneni et al; 1998). The possibility also exists for the reuse of current vegetable oil wastes such as wastes from fast food restaurants. As such, oils come from plants that can be easily grown; its production can be localized and adjusted according to demand. The conversion of the oil to fuel can therefore bring benefits to the community economically as well as making them no longer reliant on outside sources.
Over the years, vegetable oils have been substituted for diesel for use in engines but this has led to problems such as carbon deposits, oil ring sticking and gelling of the lubricating oil (Ma and Hanna, 1999). Because of such problems, research in this area has been centered on the conversion of these oils to a form that is similar to current fuels. One such fuel, which is currently gaining much attention, is biodiesel. This is a variety of ester-based oxygenated fuels made from vegetable oils or animal fats.

There are several methods for the conversion of vegetable oils to biodiesel of which the most common is the transesterification process, in which an alcohol is reacted with the oil to form esters and glycerol (Ma and Hanna, 1999). The esters are separated and commonly used as a mixture with petroleum diesel $(20: 80)$ to minimize engine modification requirements. (Altin et al; 2001), showed that vegetable oil methyl esters gave performance and emission 
characteristics close to petroleum diesel. The main problems associated with the increased use of this fuel are the costs of the oil and its processing. Also, the marketing of this product is limited to diesel engine applications.

Vegetable oils are predominantly made up of triacylglycerols with a small amount of minor compounds (2$5 \%$ ) (Cert et al; 2000). Triacylglycerols are made up of one glycerol molecule joined to 3 fatty acids by an ester link.

\section{Materials and Method}

The seeds of Cyperus esculentus L., Colocynthus vulgaris and Sesamum indicum L. seeds were collected, winnowed to remove sand and other particles, sun dried, ground using a milling machine and stored separately in dry air tight containers prior to use. Oil from the ground sample was thoroughly extracted with petroleum ether using a soxhlet extractor and separated using rotary evaporator apparatus. The extracted oil samples were transesterified into ethylesters by a method described in Ajiwe et al; 2006. Different dilutions of the ethylesters were made with petroleum diesel in the ratio of $0: 100,10: 90,20: 80,30: 70,40: 60,50: 50,60: 40$, $70: 30,80: 20,90: 10$ and 100:0. The fatty acid profiles of the ethylesters were investigated with GC-MS auto sampler and auto analyzer model fused with HP-Innowax fused with capillary column $(60 \times 60 \mathrm{mmi} . \mathrm{d})$ and helium as the carrier gas (flow rate $=1.61 \mathrm{ml} / \mathrm{min}$.). The ethylesters and their diesel blends were analyzed for parameters such as flash point, pour point, kinematic viscosity, using standard American Society for Testing and Materials (ASTM) procedures previously adopted (Ajiwe et al., 2006). The chemicals used in the experiment include, sulfuric acid (98\%wt), sodium hydroxide pellet of $98.2 \%$ purity and ethanol (analytical grade reagents).

\section{Results and Discussion}

Table 1. Fatty acid profile of Cyperus esculentus ethyl ester seed oil.

\begin{tabular}{lllll}
\hline s/no & $\begin{array}{l}\text { Common } \\
\text { name }\end{array}$ & Systematic name & $\begin{array}{l}\text { Shorthand } \\
\text { name }\end{array}$ & $\begin{array}{l}\text { R.A } \\
\text { (\%) }\end{array}$ \\
\hline 1 & Myristic acid & Tetradecanoic acid & $14: 0$ & 0.75 \\
2 & - & 9-hexadecenoic acid & & 1.12 \\
3 & Palmitic acid & Hexadecanoic acid & $16: 0$ & 24.15 \\
4 & Linoleic acid & 9,12-octadecadienoic acid & $18: 2$ & 18.04 \\
5 & Oleic acid & 9-octadecenoic acid & $18: 1$ & 36.31 \\
6 & Stearic acid & Octadecanoic acid & $18: 0$ & 17.02 \\
7 & - & Heptadecanoic acid & $18: 1$ & 2.61 \\
\hline
\end{tabular}

$\mathrm{R} . \mathrm{A}=$ relative abundance

Table 2. Fatty acid profile of Colocynthus vulgaris ethyl ester seed oil.

\begin{tabular}{lllll}
\hline s/no & $\begin{array}{l}\text { Common } \\
\text { name }\end{array}$ & Systematic name & $\begin{array}{l}\text { Shorthand } \\
\text { name }\end{array}$ & $\begin{array}{l}\text { R.A } \\
\text { (\%) }\end{array}$ \\
\hline 1 & - & Pentadecanoic acid & & 22.42 \\
2 & Linoleic acid & 9,12-octadecadienoic acid & $16: 0$ & 54.86 \\
3 & Stearic acid & Octadecanoic acid & $18: 0$ & 22.73 \\
\hline
\end{tabular}

R.A $=$ relative abundance
Table 3. Fatty acid profile of Sesamum indicum ethylester seed oil.

\begin{tabular}{|c|c|c|c|c|}
\hline s/no & Common name & Systematic name & $\begin{array}{l}\text { Shorthand } \\
\text { name }\end{array}$ & $\begin{array}{l}\text { R.A } \\
(\%) \\
\end{array}$ \\
\hline 1 & Palmitic acid & Hexadecanoic acid & $16: 0$ & 2.76 \\
\hline 2 & & Hexadecanoic acid & & 27.76 \\
\hline 3 & Cis vaccenic acid & $\begin{array}{l}\text { 11-octadecadienoic } \\
\text { acid }\end{array}$ & $18: 1$ & 9.26 \\
\hline 4 & Oleic acid & 9-octadecenoic acid & $18: 1$ & 41.09 \\
\hline 5 & & pentadecenoic acid & & 16.10 \\
\hline 6 & & heptadecanoic acid & & 3.03 \\
\hline
\end{tabular}

$\mathrm{R} . \mathrm{A}=$ relative abundance

Table 4. Saturation levels of fatty acids components of the ethylesters.

\begin{tabular}{llll}
\hline Sample & \%SFA & \%MUSFA & \%PUSFA \\
\hline Sesamum indicum & 66.67 & 33.33 & - \\
Cyperus esculentus & 57.14 & 28.57 & - \\
Colocynthus vulgaris & 66.67 & - & 33.33 \\
\hline
\end{tabular}

Table 5. Average chain length of the fatty acids components of the ethylesters.

\begin{tabular}{llll}
\hline Chain length & $\begin{array}{l}\text { Cyperus } \\
\text { esculentus }\end{array}$ & $\begin{array}{l}\text { Colocynthus } \\
\text { vulgaris }\end{array}$ & $\begin{array}{l}\text { Sesamum } \\
\text { indicum }\end{array}$ \\
\hline$\% \mathrm{C} 16$ & 100 & - & - \\
$\% \mathrm{C} 17$ & - & 33.33 & 66.67 \\
$\% \mathrm{C} 18$ & 66.67 & - & 33.33 \\
$\% \mathrm{C} 19$ & 33.33 & - & 66.67 \\
\hline
\end{tabular}

Table 1 showed that the major fatty acids present in Cyperus esculentus ethylesters were myristic acid (0.75\%), palmitic acid (24.15\%), stearic acid (17.02\%) and heptadecanoic acid (2.61) as the saturated fatty acids while 9hexadecenoic acid (1.12\%) and oleic acid (36.31\%) as the monounsaturated fatty acids, linoleic acid (18.04\%) as the polyunsaturated fatty acid.

The presence of four saturated fatty acid , 2 monounsaturated fatty acids and one polyunsaturated indicated that Cyperus esculentus ethylester can have good oxidation stability without the aid of additives to improve oxidation stability since the palmitic acid present in it is a natural anti oxidant.

Table 2 showed the major fatty acids present in Colocynthus vulgaris ethyl esters as pentadecanoic (22.42\%) and stearic acid $(22.73 \%)$ as the only saturated fatty acids while linoleic acid $(54.86 \%)$ as the only polyunsaturated fatty acid and the absence of monounsaturated fatty acids. The presence of polyunsaturated fatty acids indicated that that it has a poor oxidative stability and the possibility of polymerising at high temperature. It would therefore require an anti oxidant to prevent lipid peroxidation.

Table 3 showed the major fatty acids present in Sesamum indicum ethyl esters as palmitic acid (22.76\%), pentadecenoic acid (16.1\%) and heptadecanoic acid $(3.03 \%)$ as saturated fatty acids, while cis vaccenic acid $(9.26 \%)$ and oleic acid $(41.09 \%)$ as the monounsaturated fatty acid, with the absence of polyunsaturated fatty acid. The absence of polyunsaturated fatty acid and the presence of 
palmitic acid (a natural antioxidant) showed that it had a good oxidation stability and low possibility of polymerizing at high temperature.

Table 4 showed that Sesamum indicum and Colocynthus vulgaris ethylesters had greater percentage of saturated fatty acids than Cyperus esculentus ethylesters. Sesamum indicum and Cyperus esculentus ethylester contained no polyunsaturated fatty acid while Colocynthus vulgaris ethylesters contained no monounsaturated fatty acid.

Table 5 showed chain length by composition of Sesamum indicum ethyl esters as $\mathrm{C}_{17}(2), \mathrm{C}_{18}$ (1), $\mathrm{C}_{19}$ (2), $\mathrm{C}_{20}$ (1), Cyperus esculentus ethylester $\operatorname{as}_{16}(1), \mathrm{C}_{18}(2), \mathrm{C}_{19} 1(), \mathrm{C}_{20}$ (3) while Colocynthus vulgaris ethyl esters had chain length of $\mathrm{C}_{17}$ (1) and $\mathrm{C}_{20}$ (2).

\subsection{Variation of Flash Point of the Ethylesters and Their Diesel Blends}

Fig 1 showed the variation of flash points of Colocynthus vulgaris, Cyperus esculentus and Sesamum indicum ethylesters and their corresponding diesel blends. From the plot it was observed that Colocynthus vulgaris ethylesters and its diesel blends had the highest value of flash points, followed by Sesamum indicum then Cyperus esculentus. The high flash point value of Colocynthus vulgaris ethylesters indicated that the samples contained relatively low volatile components when compared to Cyperus esculentus and Sesamum indicum. From the plot, it was also observed that the flash point tends to increase with increase in concentration of the esters in the biodiesel blends.

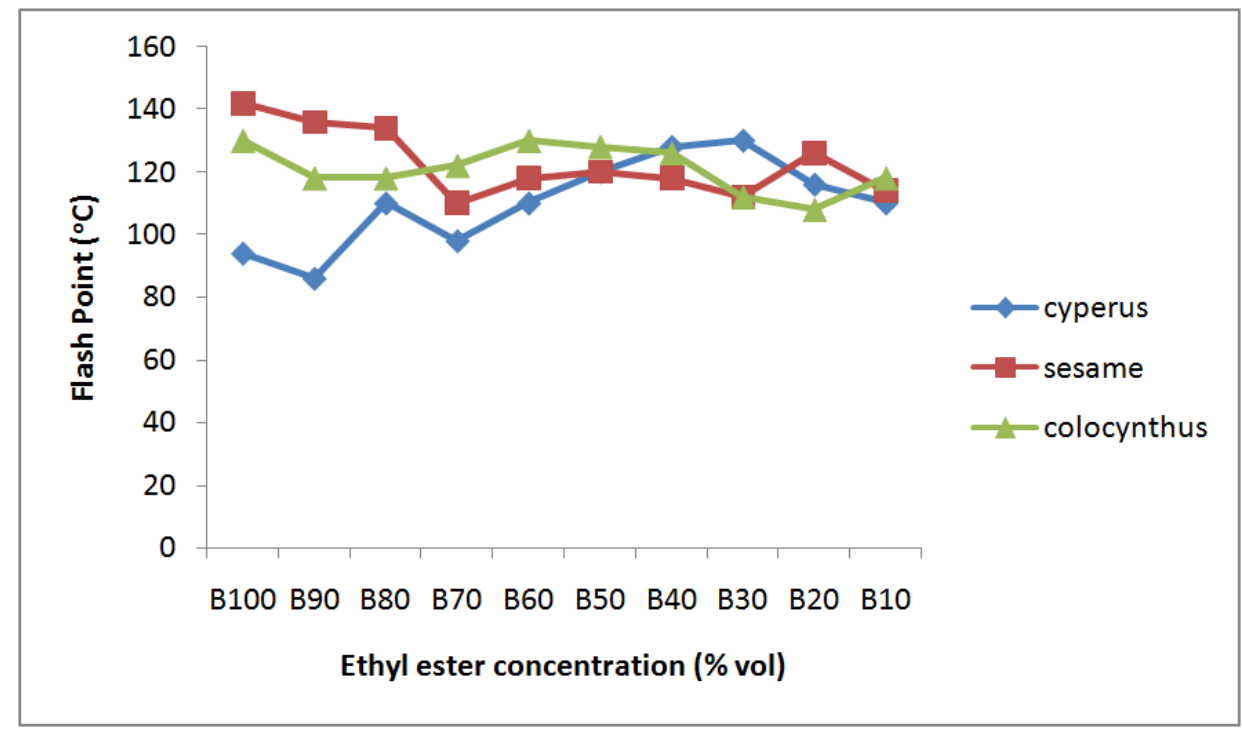

Fig. 1. plot of flash point verus Ethylester concentrations in ethylesters/diesel blends.

\subsection{Variation of Pour Point of the Ethylesters and Their Diesel Blends}

From the plot in fig 2, Cyperus esculentus ethyl ester had the poorest pour point; this result could be explained further from the result obtained in Table 1 which showed that
Cyperus esculentus ethylester contained high amount of saturated fatty acids $(57.14 \%)$. Cold flow properties could worsen with increase in degree of saturation of fatty acids (Knothe, 2007; Keith 2001, Shrestha et al; 2008).

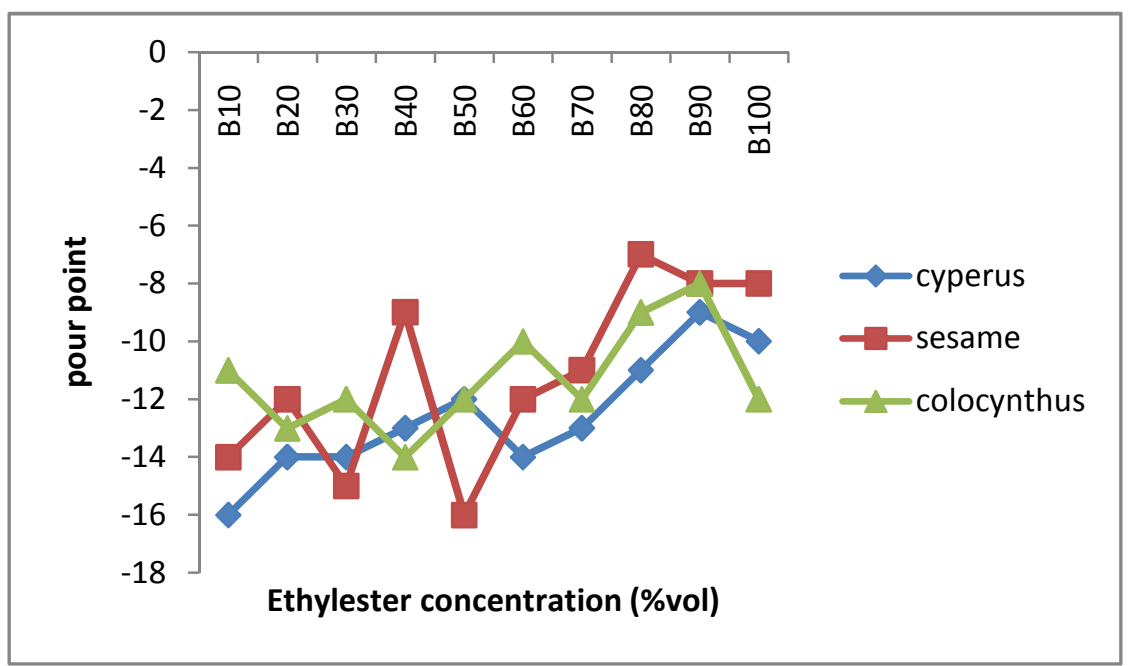

Fig. 2. Plot of pour point versus Ethylester concentrations in ethylesters/diesel blends. 
Dilution of the ethylesters decreased the pour point of the biodiesels. The ethylesters and their diesel blends were liquid at room temperature $\left(27^{\circ} \mathrm{C}\right)$ and will have no cold flow problems in countries where room temperature is always above $10^{\circ} \mathrm{C}$.

Colocyntyhus vulgaris ethyl ester showed better cold flow properties than others.

\subsection{Variation of Viscosity of the Ethylesters and Their Diesel Blends}

From the plot in Fig 3, Colocynthus vulgaris ethylester had the highest viscosity on dilution with diesel when compared to the other ethylesters at $40^{\circ} \mathrm{C}$, followed by Sesamum indicum methylesters then Cyperus esculentus ethylesters. This showed that the interaction between fossil diesel and these esters were the same and that the diesel had no or little interaction with the esters.

There was a progressive decrease in viscosity of the ethylesters blends (B10-B100), this showed that blending petrodiesel with biodiesel improves the viscosity of the blend thereby ensuring their compatibility with modern diesel engines which have fuel injection systems and are sensitive to viscosity change (Jaichander et al; 2011).

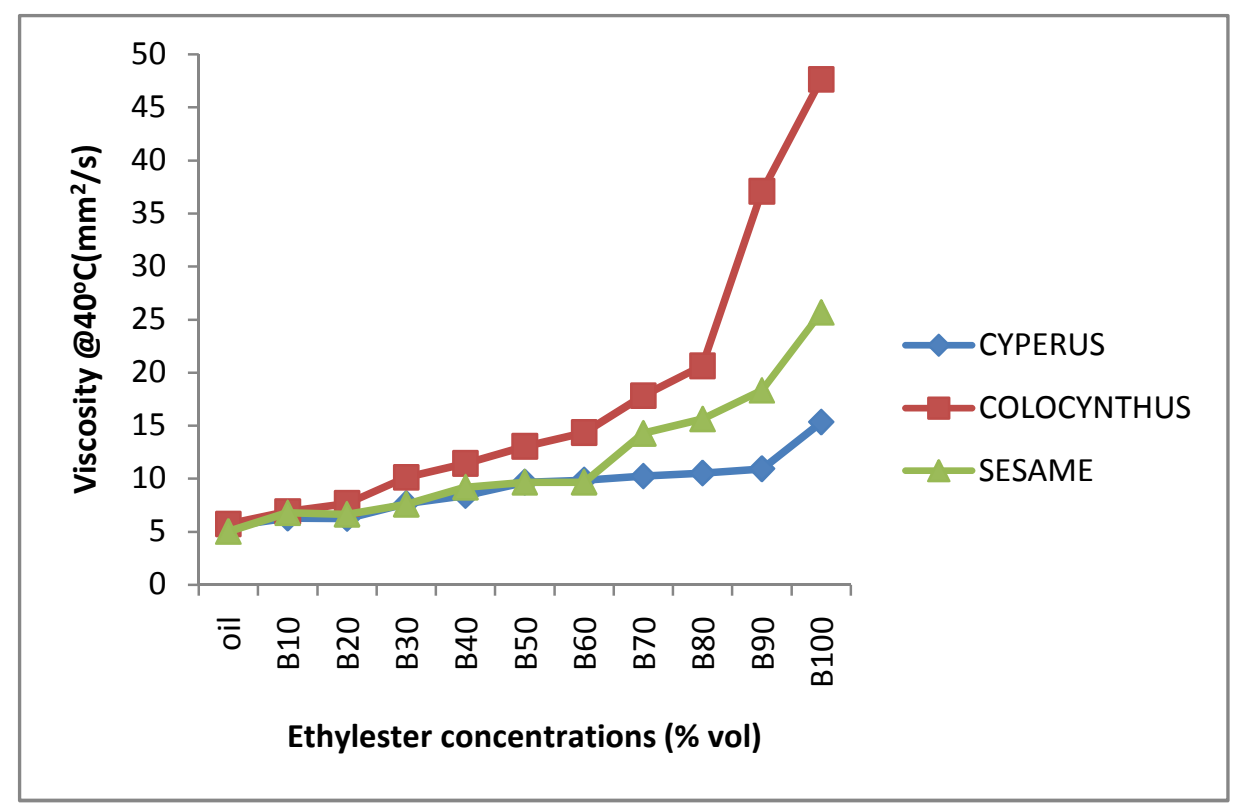

Fig. 3. plot of viscosity @ $40^{\circ} \mathrm{C}$ versus ethylester concentration in ethylester/diesel blends.

Table 6. Grading of the oils, ethylesters and its diesel blends based on their viscosities according to ASTM standards.

\begin{tabular}{llll}
\hline Ethylesters & 1D & 2D & 4D \\
\hline @ $40^{\circ} \mathrm{C}$ & & & \\
Colocynthus & - & - & $\mathrm{B} 10-\mathrm{B} 80$ \\
Sesamum & - & - & $\mathrm{B} 10-\mathrm{B} 90$ \\
Cyperus & - & - & $\mathrm{B} 10-\mathrm{B} 100$ \\
\hline
\end{tabular}

From Table 6 above, it was observed that Colocynthus vulgaris ethylesters B90-B100, Sesamum indicum B100 at $40^{\circ} \mathrm{C}$ did not fall into any grade while others fell into grade 4D diesel class (heavy diesel grades) showing that they more likely to be used as diesel fuels after heating and cooling.

\section{Conclusion}

Colocynthus vulgaris, Cyperus esculentus and Sesamum indicum ethylester were rich in saturated fatty acid than in monounsaturated fatty acids and poor in polyunsaturated indicated that these biodiesel can have good oxidation stability. The fuel properties of Colocynthus vulgaris Cyperus esculentus and Sesamum indicum biodiesel blends were better when compared to the oil and petrodiesel in terms of flash points, viscosity and pour points, hence the optimum engine performance of both oil and petrodiesel could be improved by use of these biodiesel feedstock.

\section{Acknowledgements}

We wish to express our profound gratitude to Department of Pure and Industrial Chemistry, Nnamdi Azikiwe University Awka and NARICT Zaria for their research laboratory facilities.

\section{References}

[1] Ajiwe, V.I.E., Mbonu, S.O., and Enukorah, E.A.O., (2006): Biofuel from Irvinga gabonesis seed oil and its methylesters, proceedings of the NASEF'06 International Conference, Awka, Solar Energy society of Nigeria, pp. 247-252.

[2] Ajiwe, V.I.E., Okeke, C.A., Agbo, H.U, (1995): Extraction and utilisation of Afzelia africana seed oil; Bioresources technology, Elsevier Science Limited, Britain, 53, 89-90. 
[3] Altin, R., Cetinkaya, S, Yücesu,H.S., (2001) The potential of using vegetable oil fuels as fuel for diesel engines. Energy Conversion and Management, 42: 529-538.

[4] Cert, A., Moreda, W., Pérez-Camino, M.C., (2000) Chromatographic analysis of minor constituents in vegetable oils. Journal of Chromatography, 881: 131-148.

[5] Jaichandar, S., and Annamaiia, K. (2011) The Status of Biodiesel as an Alternative Fuel for Diesel Engine- An Overview, Journal of Sustainable Energy \& Environment, 2, 71-75.

[6] Katikaneni, S. P. R., Adjaye, J.D., Idem, R.O., Bakhshi, N. N., (1998) Performance studies of various cracking catalysts in the conversion of canola oil to fuels and chemicals in a fluidized-bed reactor. JAOCS, 75: 381-391.

[7] Kaufmann, H. P., Funke, S., (1938) The field of fats. LIX. The viscometry of fats (ZurViskometrie de fette(Studien auf demfettgebiet, 59. Mitteilung.)).Fette u seifen, 45(5):255-62.

[8] Keith, A. (2001) Handmade Projects (http://joumeytoforever. org/keith_cv.htm).

[9] Knothe, G., Steidley, K. R., (2005) Kinematic viscosity of biodiesel fuel components and related compounds, Influence of compound structure and comparison to petrodiesel fuel components. Elsevier journal fuel, 84:1059-1065.

[10] Ma, F., Hanna, M.A., (1999) Biodiesel production: a review. Bioresource Technology 70: 1-15.

[11] Shrestha, D.S., Van, G., and Thompson, J., (2008) Effectiveness of Cold Flow Additives on Various Biodiesels, Diesel and Their Blends; Transactions of the ASASE, 51 (4):1365-1370. 